\title{
AVALIAÇÃO EMANCIPATÓRIA NA EJA: RELATO DE UMA EXPERIÊNCIA
}

\section{Resumo}

O presente artigo faz o relato de uma experiência acerca da avaliação na Educação de Jovens e Adultos em uma escola municipal de Gravataí/RS que atende a aproximadamente 160 educandos à noite. Para esse estudo utilizamos a entrevista compreensiva, a observação participante, além da análise documental. Os resultados apontam para distorções entre o Projeto Político Pedagógico e a prática da avaliação escolar. Tal documento, por exemplo, não registra que a avaliação na EJA seria de cunho emancipatório. Essa temática vem muito mais da fala da supervisão escolar e não dos educadores; tampouco dos educandos. Com estes, é relevante destacar o aspecto positivo dos encontros com as famílias na hora da construção dos pareceres, bem como o diálogo buscando efetivar a frequência deles em aula. Ademais, merece considerações neste trabalho o registro final das decisões tomadas pelos educadores: o boletim. A título de contribuição, sugere-se uma reconfiguração do PPP com a participação dos sujeitos envolvidos.

Palavras-chave: EJA; Avaliação; Avaliação Emancipatória

\footnotetext{
${ }^{1}$ Doutorando em Educação pela UNISINOS. Bolsista CAPES/PROEX. Participa do grupo de pesquisa Mediações pedagógicas e cidadania (PPGEdu - UNISINOS) e tambémdo Coletivo de Educação Popular e Pedagogia Social, CEPOPES (Faced-UFRGS). Endereço completo: Av. Unisinos, 950. Bairro Cristo Rei - São Leopoldo - RS, Brasil, CEP: 93.022-000. Contato: levinauter@hotmail.com.

${ }^{2}$ Doutoranda em Educação no Programa de Pós-Graduação em Educação da UNISINOS, com bolsa CAPES/PROEX. Participa do grupo de pesquisa Mediações pedagógicas e cidadania (PPGEdu - UNISINOS) e tambémdo Coletivo de Educação Popular e Pedagogia Social, CEPOPES (Faced-UFRGS).Endereço completo: Av. Unisinos, 950. Bairro Cristo Rei - São Leopoldo - RS, Brasil. CEP: 93.022-000. Contato: marilene.lemes@gmail.com.
} 


\section{INTRODUÇÃO}

A Educação de Jovens e Adultos (EJA) é um direito assegurado pela Constituição Federal, de 1988, através do artigo $3^{\circ}$ e se especificando nos artigos 206 e 208. A Lei de Diretrizes e Bases da Educação Nacional (LDB n 9394), de 1996, dá um salto qualitativo ao reconhecer formalmente a EJA em seus artigos 37 e 38. Da LDB interessa sobremaneira ao nosso texto o artigo 38 , inciso II, $\S 2^{\circ}$, no qual se lê que haverá algum tipo de avaliação. Como uma lei nacional, não há uma prescrição de como deverá ser avaliado o educando ou a educanda. E isso abre algumas possibilidades. Dentre elas, a avaliação emancipatória, tema deste texto. Entendemos que essa lei possui a perspectiva de uma pedagogia emancipatória, na medida em que instrumentaliza formalmente os sujeitos sociais para demandas da vida em sociedade, possibilitando a (re) inserção no mundo do saber escolar e ampliando suas possibilidades no mundo do trabalho. A EJA representa um desafio para o sistema educacional, aos educadores e às educadoras - um lugar de resistência à exclusão (Streck, 2013). Nessa modalidade de ensino podemos encontrar as mais diversas gerações representadas pelas múltiplas faixas etárias - que vislumbram conhecimentos capazes de romper com um ciclo de mesmice profissional em suas vidas. Em que pesem os altos índices de evasão, repetência e desistência nas séries ${ }^{3}$ cursadas, a EJA ainda se configura num espaço diferenciado no qual podem ser pensadas alternativas que busquem aferir a aprendizagem de jovens e adultos.

Entendemos importante destacar a existência de um volume considerável de trabalhos que tratam da avaliação (Loch, 2009). Tratam-na sob o viés do professor que avalia o aluno a fim de verificar se ele aprendeu (e o quanto) os conteúdos. Podemos dizer que essa avaliação tem como foco, ao fim, o planejamento das atividades docentes. A experiência de que trata este artigo vai em outra direção, pois busca trabalhar a avaliação como um instrumento que provoca à reflexão tanto o educador, a educadora quanto o educando ou a educanda.

\subsection{O lugar da experiência}

${ }^{3}$ Tenhamos em mente que a nomenclatura série é uma das possibilidades; há opções por módulo, totalidades, ciclos, entre outras. 
AVALIAÇÃO EMANCIPATÓRIA NA EJA: RELATO DE UMA EXPERIÊNCIA

A pesquisa teve lugar no município de Gravataí, no Rio Grande do Sul. Mais especificamente, foi realizada em uma escola municipal na qual diurnamente funciona o ensino fundamental, digamos, normal e, à noite, a modalidade EJA - esta desde 2005. Os trabalhos com jovens e adultos costumam ser, além de semestrais, por projetos na busca do que a equipe pedagógica considera uma forma de trabalhar com a interdisciplinaridade. Utilizamo-nos de conversas informais, chamadas por Kaufmann (2013), de entrevistas compreensivas e de observações participantes - metodologia que possibilita que o pesquisador se aproxime do seu objeto de estudo para melhor observá-lo. Esta observação participante caracterizou-se pela presença dos autores na escola acompanhando cada etapa do processo, sem, contudo, interferir nos procedimentos adotados pela escola. Ao mesmo tempo, faziam-se anotações que poderiam servir para futuras análises (Fino, 2014). As duas formas de produzir dados deixaram muito claro que para educandos e educandas o ambiente não é apenas importante porque educativo, senão também porque se tornou um espaço de convivência social.

O quadro a seguir faz um levantamento da quantidade de estudantes existentes na época das visitas, em 2013:

\begin{tabular}{|c|c|c|c|c|}
\hline Faixa-etária & Entre 15 e 20 anos & Entre 21 e 30 anos & Entre 40 e 50 anos & Acima de 50 \\
\hline TOTAL & 68 & 13 & 12 & 4 \\
\hline
\end{tabular}

Considerando que a categoria de jovem vai até quase os 30 anos de idade, vê-se, pelo quadro acima, que há uma juvenilização da EJA, conforme já apontavam Brunel (2004) e Carvalho (2010). A escola que serviu de campo empírico está localizada em um bairro cujo histórico é permeado do que se vem denominando alta vulnerabilidade social. Diante da realidade local a direção escolar, a equipe pedagógica, bem como o corpo docente optaram por desenvolver outra concepção de avaliação junto aos seus jovens e adultos. O Plano Político Pedagógico (PPP) da escola a caracteriza como sendo

uma comunidade onde predomina a economia informal - coleta de lixo para reciclagem - a principal fonte de renda advém de benefícios do Governo Federal, a Escola acolhe alunos em diferentes situações de vulnerabilidade social: mendicância, drogadição, exploração do trabalho infantil, violência sexual infantojuvenil, além de alunos com necessidades especiais. (Gravataí, 2009, p. 7). 
MIRA, L. N.; LEMES, M. A.

Diante dessa realidade, segundo o PPP, a escola tem procurado ser e fazer um diferencial a partir de "profissionais comprometidos" tendo-se em vista que "o professor não é o centro da aprendizagem e o aluno não é um mero receptor" (Gravataí, 2009, p. 7). O mesmo documento cita como uma das principais referências teóricas, o educador Paulo Freire.

Para alcançar nosso objetivo dividimos o texto da seguinte forma - além dessa introdução: (2) Breve contexto da EJA no Brasil, privilegiando uma ordem cronológica; (3) Avaliação Emancipatória, que se subdivide em Aproximação com o tema da avaliação, Compreendendo a avaliação emancipatória e Experimentando a avaliação emancipatória; e encerramos com as (4) Considerações Finais.

\section{BREVE CONTEXTO DA EJA NO BRASIL}

Não há como se chegar à EJA sem pensar, antes, no analfabetismo. Para Ana Maria Araújo Freire (1993) esse deixar algumas pessoas sem ler e escrever começou por volta de 1534. Os estudos da autora, nessa obra, vão até 1930. Outra obra, importante sobre o assunto, foi escrita por Ferraro (2009) e abrange o período de 1872 até 2000. Ambos os textos pintamnos um cenário caótico, profundamente permeado por preconceitos contra os analfabetos e as analfabetas.

É possível, então, estabelecermos que a EJA teve seu início por volta dos anos 1930, quando "a sociedade brasileira passava por grandes transformações, associadas ao processo de industrialização e concentração populacional em centros urbanos" (RIBEIRO, 2001, p. 19).

A partir de algumas pesquisas começou a haver uma superação da compreensão do processo educativo na EJA como conceito de tábula rasa. No final dos anos 1950 vozes tornaram-se audíveis e

(...) críticas convergiram para uma nova visão sobre o problema do analfabetismo e para a consolidação de um novo paradigma pedagógico para a educação de adultos, cuja referência principal foi o educador pernambucano Paulo Freire. O pensamento pedagógico de Paulo Freire, assim como sua proposta para a alfabetização de adultos, inspiraram os principais programas de alfabetização e educação popular que se realizaram no país no início dos anos 60. Esses programas foram empreendidos por intelectuais, estudantes e católicos engajados numa ação política junto aos grupos populares. Desenvolvendo e aplicando essas novas diretrizes, atuaram os educadores do MEB - Movimento de Educação de Base, ligado à CNBB Conferência Nacional dos Bispos do Brasil, dos CPCs - Centros de Cultura Popular, organizados pela UNE — União Nacional dos Estudantes, dos Movimentos 
de Cultura Popular, que reuniam artistas e intelectuais e tinham apoio de administrações municipais. (RIBEIRO, 2001, p. 22)

Então, em janeiro de 1964, foi aprovado o Plano Nacional de Alfabetização cujas orientações foram dadas pelo educador Paulo Freire. Meses depois o golpe militar interrompeu o projeto. Cabe salientar que os militares, de certa forma, também viam a necessidade de um trabalho com os adultos, talvez em razão desse assunto ter sido tomado pela opinião geral das pessoas. O resultado foi a criação do Movimento Brasileiro de Alfabetização, o MOBRAL. Com um conteúdo acrítico e sem a problematização freireana, o MOBRAL teve seu auge nos anos 1970 - quando outras ideias foram adicionadas ao Movimento: "a possibilidade de continuidade de estudos para os recém-alfabetizados, assim como para os chamados analfabetos funcionais, pessoas que dominavam precariamente a leitura e a escrita" (RIBEIRO, 2001, p. 26).

Na década de 1980, Emilia Ferreiro, educadora e pesquisadora argentina, muito contribuiu para novas visões a respeito do conhecimento; teve papel fundamental ao elucidar as quatro fases do processo de alfabetização ${ }^{4}$ : pré-silábica, silábica, silábico-alfabética e alfabética. Sua contribuição é importante até os nossos dias. São estudos como esse que contribuem para que tenhamos cada vez mais a consciência de que os educandos e educandas da EJA "são sujeitos mergulhados em variadas situações de letramento, que, via de regra, não possuem escolaridade, mas que estão iniciados em processos de alfabetização" (MOLL, 2005, p. 11). No final dessa década, em 1988, ocorreu a promulgação da Constituição Federal cujo marco está expresso no Artigo $3^{\circ}$, inciso IV, ao afirmar que entre seus objetivos fundamentais está: "promover o bem de todos, sem preconceitos de origem, raça, sexo, cor, idade e quaisquer outras formas de discriminação" (BRASIL, 2013, p. 5). Adiante, pelo menos dois artigos vão servir de baliza especialmente para a educação: o Artigo 206, que tratará da igualdade de acesso e permanência; e o Artigo 208 que garantirá acesso àqueles e àquelas que não tiveram tempo quando na idade própria.

Na metade da década de 1990 outro documento importante foi aprovado: a Lei de Diretrizes e Bases da Educação Nacional (LDB), em dezembro de 1996. Conforme dissemos na introdução, a LDBEN/96 teve, entre outros, o mérito de referendar a EJA nos Artigos 37 e 38. Desses dois, interessa sobremaneira o parágrafo $2^{\circ}$ do Artigo 38. Nele está expresso que "os conhecimentos e habilidades adquiridos pelos educandos por meios informais serão aferidos e reconhecidos mediante exames" (BRASIL, 2012, p. 26). Essa prerrogativa não

\footnotetext{
${ }^{4}$ Vide sua clássica obra "Psicogênese da Língua Escrita".
}

Revista Reflexão e Ação, Santa Cruz do Sul, v. 24, n. 3, p.229-245, Set./Dez. 2016.

http://online.unisc.br/seer/index.php/reflex/index 
MIRA, L. N.; LEMES, M. A.

encerra apenas um tipo de aferição, mas abre a possibilidade de outros modos de avaliar a aprendizagem.

\title{
3 AVALIAÇÃO EMANCIPATÓRIA
}

\subsection{Aproximação com o tema da avaliação}

Afirmamos que a escola pesquisada trabalha por projetos. Estes são semestrais, o que não significa, necessariamente, que, por exemplo, o projeto do primeiro semestre não possa ser o mesmo no segundo. Entretanto, nem o PPP nem o projeto de trabalho daquele ano (denominado "Quem ama cuida; quem cuida gosta; quem gosta protege") registram o tipo de avaliação adotada. De maneira breve o PPP dá-nos uma pista da perspectiva em que ela deverá seguir:

\begin{abstract}
A avaliação do aluno é formativa, tendo em vista atingir os objetivos da série, abrangendo os aspectos cognitivo, afetivo e psicomotor, através do registro da produção diária do desempenho e desenvolvimento da aprendizagem do aluno. A expressão dos resultados da avaliação do aluno é por Parecer Descritivo... (Gravataí, 2009, p. 13)
\end{abstract}

Mesmo de modo incipiente, é significativo que esteja registrado que a "avaliação do aluno é formativa"; mais ainda, que a expressão dos resultados será em forma de parecer descritivo. O documento denota a ideia de uma avaliação contínua, como um processo, pormenorizada e assentada na pessoalização dos educandos e das educandas. A avaliação emancipatória proposta pela professora Ana Saul (2000) segue essa mesma ideia, a de que as aprendizagens não são estanques. Lendo a autora é possível verificar o princípio básico dessa forma de avaliar: "processo de descrição, análise e crítica de uma dada realidade, visando transformá-la" (SAUL, 2000, p. 61). Espera-se que o educador ou a educadora compreenda que a avaliação equivale a "pensar com os educandos a sua vida, suas necessidades, desejos e aspirações articulados com a realidade social e cultural em que vivem e redesenhá-la num processo conjunto em que o ver, o ouvir e o agir estão interligados" (LOCH, 2009, p. 18). Essa parece ser uma forma de educação para a autonomia (Freire, 1996).

A avaliação emancipatória no contexto em que a estamos relatando é que pode permitir mudanças na realidade social de educandos e educandas, mas também na realidade cotidiana 
AVALIAÇÃO EMANCIPATÓRIA NA EJA: RELATO DE UMA EXPERIÊNCIA

de ensinagens do educador e da educadora. A escola deve ser o lugar privilegiado para o início de mudanças sociais; afinal "é nesta escola que alguns dos direitos humanos básicos devem ser promovidos e postos em prática, levando alunos (e professores) a vivenciá-los, interiorizálos e mais tarde saber defendê-los" (AFONSO, 2003, p. 86). Essa avaliação foi a opção que a equipe diretiva e pedagógica encontrou no intuito de "atender às necessidades e particularidades das classes populares, permitindo que as múltiplas vozes sejam explicitadas e incorporadas" (ESTEBAN, 2003, p. 8).

\subsection{Compreendendo a avaliação emancipatória}

A partir das entrevistas feitas com a equipe pedagógica, bem como com educadores, educadoras, educandos e educandas nos permitem duas inferências. A primeira delas é a de que os educandos e educandas pouco ou nada (e está mais para nada) sabem quanto ao tema avaliação emancipatória. A bem da verdade a eles pouco importa se é quantitativa, qualitativa, formativa ou qualquer outro nome criativo que se queira dar. Para eles importa, isso sim, que aquilo que vai registrado no Parecer ou Boletim seja inteligível e que diga se houve ou não progresso nos estudos. Ao fim e ao cabo interessa saber se passaram ou rodaram. Provavelmente seja útil repensarmos o paradigma compensatório cuja característica é marcada, em grande medida, pela repetição, nos cursos de EJA, das mesmas práticas pedagógicas que são empregadas no ensino regular, com a diferença de que o período letivo desta modalidade é menor o que conduz à precarização da ação pedagógica que se busca desenvolver. Neste sentido, persistem as noções de desqualificação, defasagem e infantilização dos educandos e das educandas que frequentam a EJA. As ideias desse paradigma se manifestam tanto nas compreensões de educadores e educadoras quanto nas compreensões dos estudantes.

A segunda inferência a que podemos chegar diz respeito ao que educadores e as educadoras sabem a respeito de uma avaliação que se propõe a emancipar. Ouviram falar de emancipação - embora não souberam dizer de modo mais sistemático o que significaria exatamente a avaliação emancipatória, nem se ela possui etapas ou não e quais seriam elas. Conversas com os professores apontaram que eles atrelavam diretamente a concepção emancipatória à visão freireana de educação - o que, no fundo, tem uma relação como veremos mais adiante. 
MIRA, L. N.; LEMES, M. A.

A equipe pedagógica, formada pela supervisora e pela orientadora educacional, foi a que mais se aproximou do proposto pela professora Ana Saul no que concerne à concepção de avaliação. Assim, para o pedagógico da escola estudada o que se pratica à noite com a EJA pode receber o nome de avaliação emancipatória.

Cabe então uma pergunta: afinal de contas, o que é efetivamente a avaliação emancipatória? O que a caracteriza? Quais são os passos que devem ser dados para que assim a avaliação de uma escola possa ser caracterizada como tal?

A resposta para esses questionamentos exige uma compreensão prévia. O livro Avaliação emancipatória: desafios à teoria e à prática de avaliação e reformulação de currículo (SAUL, 2000)é o registro de uma mudança proposta e realizada na PUC-SP. Dessa obra, interessa-nos unicamente o capítulo intitulado Criando um novo paradigma (Idem, p. 53-63). Entendemos ser essa a parte teórica aplicável à modalidade de ensino que observamos.

Basicamente, conforme Saul (2000, p. 53), a avaliação emancipatória surge fundamentada em três princípios: (1) avaliação democrática, (2) crítica institucional/criação coletiva e (3) pesquisa participante. O primeiro tem a ver com a consciência de que prestamos um serviço a uma comunidade e que devemos a ela a máxima transparência possível. Nesse sentido tanto a coleta quanto a devolução dos dados (em nosso caso, relativos à aprendizagem) devem ser em uma linguagem inteligível a essa mesma comunidade escolar. Do segundo princípio entendemos como de extrema importância a criação coletiva. Pressupomos que nessa criação deve haver o encontro entre educadores, educadoras, educandos e educandas em um diálogo no qual os que, em tese, têm uma formação mais sistematizada e formalizada possuem também a capacidade de "puxar" a crítica no momento criativo. Esse momento, para a autora, é parte de uma conscientização ${ }^{5}$ de todos os envolvidos no processo. Desse modo, a comunidade escolar precisa assumir-se como "sujeitos capazes de, criticamente, desenvolverem suas próprias ações" (SAUL, 2000, p. 55). Igualmente esse momento "inclui a verbalização e a problematização de uma dada realidade, de acordo como um particular grupo consegue apreendê-la" (Idem, p. 56). Dito de outra maneira, no contexto em que estamos refletindo nesse trabalho, a autora deixa claro que normalmente o início da

\footnotetext{
${ }^{5}$ Conscientização no sentido que Paulo Freire propõe em livro de mesmo nome. Nele, Freire destaca que: 'Quanto mais conscientização, mais se 'des-vela' a realidade, mais se penetra na essência fenomênica do objeto, frente ao qual nos encontramos para analisá-lo. (...) a conscientização é um compromisso histórico. É também consciência histórica: é inserção crítica na história, implica que os homens assumam o papel de sujeitos que fazem e refazem o mundo. A conscientização não está baseada sobre a consciência, de um lado, e o mundo, de outro; por outra parte, não pretende uma separação"(FREIRE, 1980, p. 26-27).
}

Revista Reflexão e Ação, Santa Cruz do Sul, v. 24, n. 3, p.229-245, Set./Dez. 2016.

http://online.unisc.br/seer/index.php/reflex/index 
AVALIAÇÃO EMANCIPATÓRIA NA EJA: RELATO DE UMA EXPERIÊNCIA

conversa $^{6}$ enfoca mais questões pedagógicas "abrangência e sobrecarga de programação, insatisfação difusa notada no alunado em relação ao que é desenvolvido na escola" (Idem, p. 56-57). Quebrado o gelo, por assim dizermos, o diálogo vai se aprofundando e chegando a

(...) caminhos mais profundos e complexos, que envolvem a programação, a organização educacional, o modo de convivência dos grupos na instituição, as relações de poder, os conflitos e os tabus, procurando compreendê-los e explicá-los na trama do ambiente educacional e dos contornos sociais (SAUL, 2000, p. 57)

O último princípio abordado pela autora diz respeito à pesquisa participante, uma "metodologia que procura incentivar o desenvolvimento autônomo (autoconfiante), a partir das bases e uma relativa independência do exterior" (Idem, p. 59). A ideia subjacente é a do diálogo entre as partes, com alguns cuidados. Cuidados como não ir dialogar com ideias preestabelecidas (p. 59); a importância da troca (chamada pela autora de feedback) tendo-se consciência dos diferentes papeis de cada sujeito; bem como a clareza de que "a tarefa científica pode ser realizada mesmo nas situações mais insatisfatórias e primitivas" (Idem, p. $60)$.

Pode-se dizer que, de modo geral, a avaliação emancipatória

\begin{abstract}
Caracteriza-se como um processo de descrição, análise e crítica de uma dada realidade, visando transformá-la. Destina-se à avaliação de programas educacionais ou sociais. Ela está situada numa vertente político-pedagógica cujo interesse primordial é emancipador, ou seja, libertador, visando provocar a crítica, de modo a libertar o sujeito de condicionamentos deterministas. O compromisso principal desta avaliação é o de fazer com que as pessoas direta ou indiretamente envolvidas em uma ação educacional escrevam a sua "própria história" e gerem as suas próprias alternativas de ação (SAUL, 2000, p. 61).
\end{abstract}

Esse tipo de avaliação, ainda que não explicite, baseia-se na criticidade, na busca de soluções coletivas para a transformação da realidade. A modalidade EJA, conforme já apontamos, se caracteriza pela intergeracionalidade, isto é, diversas faixas-etárias em um mesmo ambiente de aula. Essa situação requer habilidade do educador e/ou da educadora, sobretudo no que concerne às diferentes opiniões. A escola que observamos decidiu lançar mão de "métodos dialógicos e participantes;... uso de entrevistas livres, debates, análise de depoimentos, observação participante e análise documental” (SAUL, 2000, p. 63). E nos pareceu uma boa alternativa.

\footnotetext{
${ }^{6}$ Que pode ser numa sala de aula (preparada em círculo, semicírculo, com ou sem cadeiras etc.), no saguão da escola, na quadra, entre outras possibilidades. Na escola em estudo há uma sala de aula previamente organizada em semicírculo. Isso tudo depende da realidade de cada uma e de como se decide pelo local.
} 


\subsection{Experenciando a avaliação emancipatória}

A escola vem experienciando essa avaliação há seis anos. No entanto, não havia sequer um registro dessa experiência. A técnica para a obtenção dessas informações se deu a partir da entrevista compreensiva (Kaufmann, 2013), também conhecida como entrevista semiestruturada, e de observações participantes (Angrosino, 2009; Fino, 2003).

Conversar com a equipe pedagógica da escola foi importante, sobretudo porque houve um diálogo aberto e sem meias palavras; a nosso ver sem os costumeiros subterfúgios que intentam velar os equívocos, as incongruências e entraves comuns, em se tratando de relações interpessoais. As observações participantes também foram relevantes na medida em que se consubstanciavam na prática.

A orientadora educacional, com experiência na EJA em outras escolas e tendo sido, inclusive, assessora pedagógica nessa modalidade de ensino junto à Secretaria Municipal de Educação (SMED), destacou um diferencial entre a escola que estamos estudando e as demais no município. Disse que há uma avaliação diagnóstica, após o início de cada semestre, cujo objetivo é dar noção ao educando e à educanda daquilo que lhe falta para obter êxito no final. Uma iniciativa que, segundo ela, dá subsídios à orientação visando a um trabalho mais efetivo com as famílias e/ou responsável pelos/as estudantes menores de idade (atualmente a maioria na modalidade).

Com a supervisora escolar tivemos mais detalhes de como se organizam as reuniões. Não poderia ser diferente; afinal, pelo menos em tese, ela é quem tem a incumbência de liderar a formatação e a continuidade do pensamento pedagógico da instituição mediante as formações continuadas. Sobre o processo avaliativo, ela nos deu uma espécie de passo a passo de como ele ocorre. E seu processo está dividido em três etapas distintas: avaliação/perfil do professor em relação à turma; avaliação/perfil da turma com suas especificidades e avaliação final. A seguir apresentamos cada etapa seguida pela escola.

\section{Avaliação/perfil do professor $\mathrm{x}$ alunos}


AVALIAÇÃO EMANCIPATÓRIA NA EJA: RELATO DE UMA EXPERIÊNCIA

Aproximadamente trinta dias após o início de cada semestre, havia uma conversa individual com cada professor ${ }^{7}$. Trabalho este chamado de assessoria individual cujo registro era feito em ata. O objetivo era, sobretudo, perceber, direta ou indiretamente, como andam as relações entre o professor e seus alunos. A meta era que, na medida do diálogo, fosse se descortinando os discursos dos professores em relação a seus alunos sob dois prismas: no que se referia à relação interpessoal (se se respeitavam, se um atendia ao outro quando chamado; quais conflitos estariam latentes, quais os históricos de vida atrelados) e, com mais ênfase, no que concerne a aprendizagem (quais conteúdos haviam sido dominados, quais defasagens existiam). A respeito do conteúdo desse momento nem aluno nem responsável teriam acesso, tampouco saberiam desse acontecimento na escola. Ou seja, seria privilégio da supervisão escolar possuir esses registros, pois poderiam servir de temas para eventuais ou futuros encontros de formação continuada.

\section{Avaliação/perfil da turma}

Passado um tempo maior de aulas, geralmente na metade do semestre, ocorria a segunda etapa da avaliação. Mais uma vez o aluno não tinha acesso ao que era tratado - no momento em que estivesse acontecendo essa etapa. O encontro tinha como finalidade maior focalizar o alunado ou, melhor, a aprendizagem deles. Em datas previamente agendadas, professores, por turma, se reuniam com a equipe pedagógica a fim de traçar o perfil das turmas no que tangia aos conteúdos desenvolvidos e os previstos para desenvolvimento. Cada professor, normalmente obedecendo à lista de chamada, comentava aspectos da aprendizagem de seus alunos: assiduidade, comprometimento ou não com os estudos, se atentara ou dispersara-se em sala de aula, se a conversa atrapalhara ou não (e até que ponto) na sua aprendizagem, quais defasagens de conteúdos precisariam ser sanadas, entre outras demandas. Com base nessas conversas era que a equipe pedagógica elaborava o que a escola vinha chamando de avaliação diagnóstica. Feito o documento, marcava-se uma data na qual haveria a distribuição dessas avaliações aos respectivos alunos, se maiores de idade, ou ao seu responsável, se menores. Marcada a data, a supervisão e a orientação escolar teriam papel

\footnotetext{
${ }^{7}$ A terminologia utilizada pela escola é essa mesma: professor, independentemente de ser homem ou mulher; o mesmo valendo para o termo aluno. Optamos por deixar assim no texto para, de algum modo, marcarmos essa diferença. Ao longo do nosso texto (isso se verifica mais facilmente em outros subcapítulos), no entanto, preferimos, como um sinal mínimo de respeito, denotar os dois gêneros.
} 
MIRA, L. N.; LEMES, M. A.

importante junto aos alunos e/ou responsável por aqueles menores de idade. A elas daria-se a incumbência de 'chamar o aluno' para a realidade, isto é, dizer claramente no que o/a estudante haveria de melhorar para a continuidade de avanços nos estudos. Era o instante em que poderiam ocorrer algumas combinações entre o aluno e a família a fim de que ambos se comprometessem visando à melhoria nos estudos e, por conseguinte, melhorassem os resultados de provas, testes e trabalhos.

\section{Avaliação final}

A construção da avaliação é geralmente um momento que carrega uma tensão, uma mescla de euforia com expectativa. O semestre está sendo finalizado quando se chega à avaliação final. Nela será possível perceber até que ponto as outras duas etapas tiveram recepção. Também será o instante no qual a escola (ali representada pela equipe diretiva e pedagógica, além do corpo docente) terá uma radiografia, um feedback dado pelos pais e pelos alunos, quanto a ter atingido ou não intentos tanto do corpo docente quanto do discente.

A direção da escola normalmente iniciou esse momento de diálogo, saudando a todos os presentes, bem como ratificando a importância daquele encontro, chamando a atenção para a relevância de momentos nos quais todos os envolvidos no processo de ensino e aprendizagem poderiam dizer a sua palavra. A equipe diretiva também aproveitava o instante para dar informes importantes: data de rematrícula, período de inscrições para alunos novos, horários da secretaria etc.

Em seguida passava a palavra para a equipe pedagógica. Esse era o instante em que o serviço de orientação escolar relatava brevemente os levantamentos e/ou encaminhamentos feitos pelo setor que objetivaram diminuir a infrequência, as chegadas com atraso em sala de aula - por exemplo. Feitas as considerações, sob a coordenação da supervisão escolar, abriase um espaço, por turma, para que as famílias (pais/responsável) expressassem suas impressões relativas à EJA, à como andaram os trabalhos ao longo do semestre, à como perceberam a aprendizagem dos filhos, a sugestões (as mais diversas possíveis) que eventualmente surgissem. Aos alunos maiores de idade também lhes era dada oportunidade de falar a respeito dos mesmos tópicos ou a acrescentarem algum outro que não havia sido abordado. Os apontamentos feitos durante as falas, pela orientadora ou pela supervisora, serviriam de matéria-prima para futuras formações e/ou reflexões. Avançando nos trabalhos, era chegada a vez do corpo docente explicitar ao aluno seu avanço (nesse caso, por exemplo, 
AVALIAÇÃO EMANCIPATÓRIA NA EJA: RELATO DE UMA EXPERIÊNCIA

tornando claro algumas deficiências que ainda careceriam de superação, bem como os desafios que o esperarão na série seguinte) ou sua retenção (caso em que o/a retido/a deverá assumir alguns compromissos e superar dificuldades por ora intransponíveis) na série.

Embora não esteja escrito em lugar algum, a observação participante e as entrevistas compreensivas apontaram que as reflexões devem igualmente abranger o professor - ele terá novos desafios ao encontrar alunos novos na série que serão somados aos eventuais retidos. Ainda que possa soar repetitivo, os professores têm a competência e até o compromisso ético de retomarem assuntos eventualmente já abordados, tais como o adequado e/ou inadequado planejamento do professor, as questões relativas ao comportamento dos alunos na sala de aula, o cumprimento de prazos para a entrega de trabalhos, além dos inevitáveis comentários a respeito do comportamento em sala de aula. O parecer descritivo final, no entanto, nada diz sobre os diálogos, digamos, mais francos e menos confortáveis evidenciados em tais encontros. Ou seja, parecer final como que abranda 'os sintomas do aluno' e fixa-se bem mais em dizer sucintamente se houve ou não progressão nos estudos.

Uma última nota sobre a avaliação final diz respeito ao momento pós-discussão. Alunos e pais são liberados/dispensados. Ficam na sala apenas o grupo de professores juntamente com a equipe pedagógica. Elaborados os pareceres finais, agenda-se uma data para a entrega de tais documentos. No ato de entrega, o aluno maior de idade e/ou o responsável pelo menor assinam uma folha comprobatória do efetivo recebimento do parecer descritivo final.

\section{CONSIDERAÇÕES FINAIS}

É importante relembrarmos que a escola abordada neste texto, com um contingente importante de jovens, mais do que com adultos, optou por trabalhar a partir de uma metodologia que nos parece bem mais propensa e provocadora do diálogo. Não menos importante é realçar que o documento que balizou essa prática não a detalhou. Como vimos na introdução, o PPP apenas destaca que o educador ou a educadora deveriam ser comprometidos e terem a consciência de não serem o centro da aprendizagem.

Avançando na leitura do texto, chegou-se a um breve contexto no qual se situa a EJA uma modalidade de ensino que visava ao aceleramento da aprendizagem para aqueles e aquelas que no tempo ideal, por diversas razões, não tiveram acesso. Nessa mesma cronologia que apontamos, dissemos da importância dos estudos científicos que trouxeram novo entendimento, por exemplo, às fases da alfabetização. Atualmente, vivemos uma compreensão 
MIRA, L. N.; LEMES, M. A.

de que muitos, embora alfabetizados, mal compreendem o que leem. Na atualidade fala-se de letramento, isto é, na capacidade de ler e entender o que se leu. Nosso entendimento é que a perspectiva da avaliação emancipatória colabora sobremaneira para o letramento, na medida em que provoca o debate, a reflexão e a tensão entre os temas trabalhados em sala de aula e a apreensão desses conteúdos por parte de educandos e educandas.

O tema central deste artigo, a avaliação emancipatória, careceu de três subdivisões. Primeiro para dizermos que o PPP da escola não caracterizou nenhum tipo de avaliação; não deu nenhum nome aos procedimentos que realizava. Segundo, era necessário caracterizar teoricamente os procedimentos adotados - desde as primeiras reuniões até que educandos e educandas recebessem o chamado parecer descritivo. Terceiro para a apresentação das etapas que cada procedimento ensejava. Todos esses momentos evidenciam o quanto a escola foi original em adotar um modelo de avaliação que privilegiou a realidade local a que a escola estava inserida. As observações participantes demonstraram que os educadores e as educadoras tinham pleno conhecimento dos procedimentos avaliativos da escola. No entanto, jamais atrelavam-nos à avaliação emancipatória (SAUL, 2000). Estamos propensos a considerar que isso tem a ver com o desconhecimento da proposta de Saul (2000), mas também e sobretudo com a falta dessa referência no PPP.

Para finalizar reforçamos que tão importante quanto a teorização a respeito de determinada teoria é a prática. Essa escola, localizada em Gravataí, experienciou uma prática que ao grupo de educadores e educadoras fazia sentido, bem como para educandos e educandas, independentemente da existência ou não de uma teoria. Provavelmente essa seja a razão para que a prática, de algum modo, não apenas ultrapasse a teoria como também torna a experiência original.

Nesse contexto ganha sentido a máxima de que "mudar é difícil, mas é possível" (FREIRE, 1996, p. 79). Em que pese estar inserida em um contexto de muita violência, de evidenciar mais jovens que adultos - uma tendência já apontada por Brunel (2004) e por Carvalho (2010) - a avaliação emancipatória na educação de jovens e adultos pode ser o início de um olhar diferente nessa modalidade de educação.

\section{EVALUACIÓN CRÍTICA EN LA EDUCACIÓN DE JÓVENES Y ADULTOS: RELATO DE UNA EXPERIENCIA}

\section{Resumen}


Este artículo es una descripción de un experimento sobre la evaluación en educación de jóvenes y adultos en una escuela en Gravataí / RS, Brazil, con cerca de 160 estudiantes en la noche. Para este estudio se utilizó la entrevista comprensiva, la observación participante, además de estudios documentales. Los resultados apuntan a distorsiones entre el proyecto político pedagógico y la práctica de la evaluación escolar. Ese documento, por ejemplo, no registra que la evaluación en la educación de adultos sería de naturaleza emancipadora. Este tema viene mucho más de la supervisión y no de los educadores de las escuelas; ni de los estudiantes. Con eso, es importante destacar el aspecto positivo de la reunión con las familias en el momento de la construcción de opiniones y el diálogo que intenta efectuar la frecuencia de ellos en clase. Por otra parte, merece una consideración en este trabajo el registro final de las decisiones tomadas por los educadores: el boletín informativo. Como una contribución, se sugiere que una reconfiguración del PPP con la participación de los sujetos implicados.

Palabras-clave: EPJA; Evaluación; Evaluación Crítica

CRITICAL EVALUATION IN THE ADULT AND YANG PEOPLE EDUCATION: REPORT OF AN EXPERIENCE

\begin{abstract}
The following article is about the experience on evaluation at YAE (Young and Adult Education) at a municipal scholl in Gravataí/RS, Brazil, which attends approximately 160 students on the evening shift.This study has made use of the understanding interview, the participant observation, furthermore the documents analysis. The results point to distortions between the Political Project (PPP) and the school evaluation practice. Such document, for instance, does not register that the evaluation at YAE woul be in the emancipatory kind. The thematic is much more based on the school supervisors' speech than on the teachers', students neither. With such, it is relevant to remember the positive aspect on the family meetings in the time of the reports' construction, as well as the positive aspect on the family meetings in the time of the reports' construction, as well as the dialogue searching to reassure their presence in class. Moreover, the final registration of decision making made by the teachers deserves
\end{abstract}


MIRA, L. N.; LEMES, M. A.

consideration: the report card. In the ways of contribution, it is suggested a reconfiguration of the PPP with the participation of the subjects involved.

Keywords: Youth and Adult Education; Evaluation; Critical Evaluation

\section{REFERÊNCIAS}

AFONSO, Almerindo Janela. Escola pública, comunidade e avaliação: resgatando a avaliação formativa como instrumento de emancipação. InESTEBAN, Maria Teresa (Org.). Avaliação: uma prática em busca de novos sentidos. 5. ed. Rio de Janeiro: DP\&A, 2003.

ANGROSINO, Michael. Etnogafia e observação participante. Porto Alegre: Artmed, 2009.

BRASIL. Constituição (1988). Constituição da República Federativa do Brasil. Brasília, DF, Senado, 2013. Disponível em:

<www.senado.gov.br/legislacao/const/con1988/CON1988_05.10.1988/CON1988.pdf>Acesso em: 01 jun. 2013

. LDB: Lei de Diretrizes e Bases da Educação Nacional: lei n. 9.394, de 20 de dezembro de 1996, que estabelece as diretrizes e bases da educação nacional. 7.ed. Brasília: Câmara dos Deputados, Coordenação Edições Câmara, 2012.Disponível em:

<http://www.riogrande.rs.gov.br/smed/wp-content/uploads/2013/04/ldb_7ed.pdf >. Acesso em: 01 jun. 2013

BRUNEL, Carmen. Jovens cada vez mais jovens na educação de jovens e adultos. Porto Alegre: Mediação, 2004.

CARVALHO, Roseli Vaz. A Juventude na educação de jovens e adultos: estudo das práticas pedagógicas no ensino fundamental, fase II, e ensino médio. 2010. 223f. Dissertação (Mestrado em Educação) - UTP, Curitiba.

ESTEBAN, Maria Teresa. A avaliação no cotidiano escolar. InESTEBAN, Maria Teresa (Org.). Avaliação: uma prática em busca de novos sentidos. 5. ed. Rio de Janeiro: DP\&A, 2003.

FERRARO, Alceu Ravanello. História inacabada do analfabetismo no Brasil. São Paulo: Cortez, 2009.

FINO. Carlos Manuel Nogueira. FAQs, etnografia e observação participante. Revista europeia de etnografia da educação. - Funchal : Sociedade Europeia de Etnografia da Educação, n. 3, 2003. Disponível em: <http://hdl.handle.net/10400.13/498>. Acesso em: 01 maio 2014.

FREIRE, Ana Maria Araújo. Analfabetismo no Brasil: da ideologia da interdição do corpo à ideologia nacionalista, ou de como deixar sem ler e escrever desde as Catarinas (Paraguaçu), 
AVALIAÇÃO EMANCIPATÓRIA NA EJA: RELATO DE UMA EXPERIÊNCIA

Filipinas, Madalenas, Anãs, Genebras, Apolônias e Grácias até os Severinos. 2. ed. São Paulo: Cortez, 1993.

FREIRE, Paulo. Conscientização: teoria e prática da libertação, uma introdução ao pensamento de Paulo Freire. São Paulo: Moraes, 1980.

Pedagogia da Autonomia: saberes necessários à pratica docente. 27. ed. São Paulo: Paz e Terra, 1996.

GRAVATAÍ. Prefeitura Municipal de Gravataí, Secretaria Municipal de Educação, Escola Municipal de Ensino Fundamental Nova Conquista. Plano Político-Pedagógico. Gravataí: 2009.

KAUFMANN, Jean-Claude. A entrevista compreensiva: um guia para pesquisa de campo. Petrópolis: Vozes; Maceió: Edufal, 2013.

LOCH, Jussara Margareth de Paula. Planejamento e avaliação em EJA. In: LOCH, J. M. P. et al. EJA: planejamento, metodologias e avaliação. Porto Alegre: Mediação, 2009.

MOLL, Jaqueline (org.). Educação de jovens e adultos. 2. ed. Porto Alegre: Mediação, 2005.

RIBEIRO, Vera Maria Masagão (coord.). Educação para jovens e adultos: ensino fundamental: proposta curricular $-1^{\circ}$ segmento. São Paulo: Ação Educativa; Brasília: MEC, 2001.

SAUL, Ana Maria. Avaliação emancipatória: desafios à teoria e à prática de avaliação e reformulação de currículo. 5. ed. São Paulo: Cortez, 2000.

STRECK, Danilo Romeu. Territórios de resistência e criatividade: reflexões sobre os lugares da Educação Popular. In STRECK, Danilo R.; ESTEBAN, Maria Teresa (Orgs.). Educação popular: lugar de construção social coletiva. Petrópolis: Vozes, 2013.

Data de recebimento: $15 / 03 / 2016$

Data de aceite: 17/10/2016 